\title{
Miyokard İnfarktüsü Sonrası Kadınlarda Cinsel Yaşam
}

\author{
Sexual Activity of Women Following Myocardial Infarction
}

\author{
Gülşah ÇAMCI*, Gülbeyaz CAN**
}

İletişim/Correspondence: Gülşah ÇAMCI Address / Address: Kocaeli Üniversitesi, Araştırma ve Uygulama Hastanesi Umutetepe Kampüsü İzmit/Kocaeli Tel: 02623038747 E-mail: gulsah_camci@hotmail.com

\section{$\ddot{O} Z$}

Miyokard infarktüsü sonrası kadınlarda cinsel yaşamı değerlendirmek için yapılan çalışmalar sinırlıdır. Yapılan çalışmalarda; cinsel aktivitenin tek başına miyokard infarktüsü tetikleme riski düşüktür (<\%1). Miyokard infarktüsü sonrası yaşanan reinfaktüs korkusu, anjina, anjina korkusu, depresyon gibi nedenlerle kadınları \%50-80'inin cinsellikten kaçındığı bulunmuş̧ur. Sağlık personelleri tarafindan da miyokard infarktüsü sonrası yeterince cinsel eğitimin verilmediği saptanmıştır. Sonuç olarak; miyokard infarktüsü sonrası kadınların cinsel yaşamı daha kapsamlı araştırılarak gerekli cinsel ĕgitimin verilmesi sağlanmalıdır.

Anahtar Kelimeler: Cinsellik, kadında cinsellik, miyokard infarktüsü.

\section{ABSTRACT}

Studies to evaluate the sexual life of women after myocardial infarction is limited. Studies, triggering risk of myocardial infarction by sexual activity is low (<\%1). It is found that $50-80 \%$ of women avoided sex by reasons such as being the fear of re-infarction, angina, fear of angina, depression after myocardial infarction. Sex education given by health professionals after myocardial infarction has been identified not enough. As a result; sexual life of women following myocardial infarction should be given to investigate more comprehensive, grant of the required sex education must be provided for women.

Key Words: Sexuality, sexuality in women, myocardial infarction.

\section{GíRiş}

Cinsel yaşam, bireyin yaşamında önemli boyutlardan biridir. Bazıları için cinsellik, yaşamının önemli bir bölümünü oluştururken, bazılarında çok az bir bölümünde yer almaktadır (Aygın ve Aslan 2008; Özdemir 2010). Cinsel açıdan aktif kişilerin çoğu için cinsel birleşme yaşamdaki en keyifli, tatmin edici ve gerginliği giderici etkinliktir (Y1ldız ve Pınar 2004). Abraham Maslow'un temel insan gereksinimleri kuramında üçüncü sırada yer alan sevgi ve ait olma gereksiniminde, cinsellik de vurgulanmıştır (Merrigan
1998; Morimoto 2011). Cinsellik bireyin kültürel özelliklerine göre farklılık göstermektedir. Kültürel özelliklerinin yanı sıra bazen cinsel yaşam hastanın geçirdiği önemli bir hastalık sonucunda da değişebilmektedir. Diyabet, kardiyovasküler hastalıklar, cerrahi operasyonlar, depresyon gibi çeşitli nedenlerle cinsel fonksiyonlar kesintiye uğrayabilir (Yıldız ve Pınar 2004). Hastaların cinsel yaşamının değişmesine neden olan hastalıklardan biri miyokard infarktüsüdür (MI) (Yıldız ve Pınar 2004; Yılmaz ve Pınar 2005).

*Uzm. Hemşire Kocaeli Üniversitesi, Araştırma ve Uygulama Hastanesi, Aritmi Servisi, ${ }^{* *}$ Doç. Dr. İstanbul Üniversitesi Florence Nightingale Hemşirelik Fakültesi

Yazının gönderilme tarihi: 06.12.2012

Yazının basım için kabul tarihi: 18.04.2014 
MI geçirmiş kadınlarla yapılan çalışmalar sınırlıdır. Bunun nedenleri; genç kadınlardaki akut MI ve koroner arter hastalığı prevelansının düşük olması, büyük örneklem gruplarına ulaşılamaması, kadının özellikle yaşı ilerlemiş kadının çalışma hayatında ve toplumdaki olumsuz cinsel alg1 ve mitlerin yer almasidır (Merrigan 1998).

\section{Cinsel Aktivite Sırasında Miyokard İnfarktüsü}

Cinsel aktivite esnasında MI'ın nasıl meydana geldiği tam olarak bilinmemekle beraber en çok kabul gören teori şu şekildedir: Öncelikle hemodinamik stres artışı (sempatik sinir sistemi artar) olur. Buna bağlı kan basınc1, kalp hızı ve sonuçta da miyokardın oksijen tüketimi artar ve vazokonstrüksiyon olur. Takiben trombositlerin agregasyonu da artar ve koroner arterlerde bulunan aterom plaklarında rüptür ve kopma meydana gelir (Chen, Zhang ve Tan 2009; Muller, Abela, Nesto ve Tofler 1994). Bu teoriye dayanarak, kalp hızını ve kan basincinı azaltan ve trombosit agregasyonunu inhibe eden ilaçlar MI'ya bağlı oluşan riski azaltacaktır (Taylor 1999).

Cinsel aktivitenin MI'yı tetikleyebileceği kabul edilmektedir, ancak risk oldukça düşüktür $(<\% 1)$ (Muller, Mittleman, Maclure, Sherwood ve Tofler 1996). MI sonrası yaşanan reinfaktüs korkusu, anjina, anjina korkusu, depresyon gibi nedenlerle cinsellik etkilenmektedir. Cinsel aktivite sırasında gelişen iskemik olayların hepsi kalp hızındaki artışla ilişsili (Stein 2000) olup, bu durum ilaç tedavisi (beta-bloker ajanlar vb.), rehabilitasyon programları ve revaskülarizasyon yöntemleri aracılığı ile azaltılabilir.

Cinsel aktivite sırasında ve sonrasında yaklaşık iki saat içinde MI geçirme olasılığ ${ }_{1}$ artar. Özellikle bu alış1lmış eforu düşük olanlarda MI oranı 2,5 kat daha fazla görülebilmektedir (Muller ve ark. 1996).

Bununla birlikte cinsel aktivitenin MI'y1 tetikleyebileceği düşünüldüğünden [Rölatif Risk (RR) 2,70 (1,484,91)], hastalar MI sonrası cinsel yaşamlarını sonlandirabilmektedir (Dahabreh ve Paulus 2011).

\section{Miyokard İnfarktüsü Sonrası Kadınlarda Cinsel Yaşam}

Kalp krizi sonrasında hem hastalar hem de partnerleri cinsel aktivitede dahil olmak üzere tamamen normal yaşamlarına geri dönmeleri konusunda oldukça endişeli ve çekimserdirler. Pek çok çift hatalı olarak cinsel aktiviteyi riskli ve tehlikeli bulabilmektedir (Yıldız ve Pınar 2004; Yılmaz ve Pinar 2005). Erkek ve kadınlarda MI sonrası cinsel aktivite sıklığı ve doyumunda belirgin bir azalma olduğu rapor edilmektedir (Drory, Kravetz ve Weingarten 2000). Miyokard infarktüsü sonrası kadınlarda cinsel aktivitenin etkilenmesi; kadınların, kadın olarak bir yanını eksik görebilmesine neden olabilmektedir. Eşinin cinsel isteğini karşılamadığı için sıkıntı yaşayabilmekte ve çocuk sahibi olmak istemeleri bu sıkıntıyı artırabilmektedir. Kadınların cinsel memnuniyeti, sıklığı azalmaktadır. Kadınlar da stress ve anksiyeteye neden olabilmektedir. Evde, işinde ve sosyal hayatında aldığı işlerden doyum alamamaktadır. Hastaların yaşam kalitesi düşmektedir.

Yıldız ve Pınar (2004)'ın yaptığı çalışmaya 36 kadın, 66 erkek toplam 102 MI hastası katılmıştır. Bu çalışmada olguların \%70,6'sının son bir ayda cinsel ilişkiye girdiği, \%29,4'ünün cinsel ilişkiye girmediği belirlenmiştir. MI sonrası cinsel ilişki yaşayan olguların \%32,4'ünde cinsel aktivite tatmininde, \%53,9'unda ise cinsel aktivite sıklığında azalma olmuştur. MI sonrası cinsel ilişki sıklığında azalma nedenleri sorgulandığında olguların \%85,5'inde reinfarktüs korkusu, $\% 9,1$ 'nde reinfarktüs korkusu ile birlikte anjina varl1ğ1, \%5,5'inde ise sadece anjina olduğu saptanmıştır. Çalışmada kadınların \%80'inde cinsel disfonksiyon bulunmuştur.

Drory ve ark.'nın MI geçirmiş erkek ve kadınlarda cinsel yaşamlarını karşılaştırmış. İlk kez MI geçirmiş kadın ve erkek hastalar, hastaneden taburcu olmadan önce, taburcu olduktan üçüncü ve altıncı aylarda hastalarla görüşülmüştür. Çalışmaya 51 kadın (yaş ortalaması 56) ve 462 erkek hasta katılmıştır. Akut MI öncesi aktif cinsel yaşamı olmayan 35 kadının hiçbirinde cinsel yaşam devam etmemiştir. Çalışmada kadınla- 
rın \%7'si ilk akut MI sonrası üçüncü ve altıncı aylarda cinsel aktivitelerini devam ettirdiklerini rapor etmişlerdir (Drory, Kravetz, Florian ve Weingarten 1998). Başka bir çalışmada, MI geçiren 26 kadında cinsel disfonksiyon, \%68 bulunmuştur. Cinsel ilişki prevelansının azalmasındaki en önemli nedenleri; \%54,3 reinfarktüs korkusu, \%24,3 ölüm korkusu, \%42,9 ağr1, $\% 45,7$ yorgunluk bulunmuştur (Özer, Bektas, Arikan ve Vicdan 2011).

Almanya'nın beş kalp damar hastanesinin ayaktan rehabilitasyon merkezinden 493 (395 erkek ve 98 kadın) hastanın katıldığı bir çalışmaya göre; kadınların \%43,1'inde seksüel disfonksiyon görülmüştür. Ayr1ca kardiyovasküler problemli kadınlardaki cinsel disfonksiyon prevelansı, sağlıklı kadınlara göre iki kat daha fazla olduğu belirtilmiştir (Kriston, Günzler, Agyemang, Bengel ve Berner 2010).

Yapılan bir çalışmada; ST segment yükselmesi olmayan MI ve unstabil anjinaya sahip 35 kadın hastanın katıldığ 1 bir çalışmada, öncelikle bütün hastalar kardiyak rehabilitasyon eğitimi almış ve taburculuktan 12 hafta sonra hastaların cinsel aktiviteleri değerlendirilmiştir. Hastaların \%48,57'si cinsel aktivitelerini devam ettiği, ama cinsel aktivesi devam eden hastaların çoğu cinsel aktivitelerinden memnun olmadığ 1 , $\% 51,43$ hasta henüz cinsel aktiviteleri devam etmediği bulunmuştur. Cinsel aktivitesi devam eden hastaların \%70,59 kardiyak rehabilitasyon programını tamamlamış ve cinselliği devam etmeyenlerin \%38,89 tamamlamıştır. Buna gore; rehabilitasyonlu hastalar rehabilitasyonlu almayan hastalara göre 3,77 kez daha cinsel aktivitelerini devam ettirmiştir (Eyada ve Atwa 2007).

Papadopoulus ve ark.'nın 130 MI geçirmiş kadında (38 ve 65 yaş arası, ortalama yaş 53,8 ) yaptıkları çalışmada ise; kadınların \%51'inin ve eşlerinin \%44'ünün cinsel ilişki sırasında korku yaşadıklarını rapor edilmiştir. MI sonrası cinsel aktivite hastaların \%27'sinde devam etmemiş, \%44'ünde değişiklik olmamış, \%44 kadın hastada azalma olmuştur. Kadınların \%50'sinden fazlası cinsel ilişki sırasında göğüs ağrısı, çarpınt1, terleme ve yorgunluk gibi semptomlara sahip ol- muştur. Kadınların 84'ü MI öncesi aktif cinsel yaşama sahipmiş ve yaklaşı \%34 cinsel aktiviteyi devam ettirmekte endişe yaşamıştır. Kadınları 48'i MI sonraS1 cinsel danışmanlık almıştır ve 61'i MI sonrası cinsel aktivitelerini devam ettirmiştir (Papadopoulos, Beaumont, Shelley ve Larrimore 1983).

Papadopoulos'un başka bir çalışmasında MI sonrası kadınlarda cinsel aktiviteyi devam ettirme $\% 72$ bulunmuştur (Drory ve ark. 2000).

Hamiltan ve Seidman (1993)'nın 20 kadın ve 42 erkek MI geçirmiş hastada yaptığı çalışmada; kadınların cinsel aktivite sıklığ 1 ve memnuniyetinin azaldığ 1 bulunmuştur.

Altıok ve Yılmaz (2011), MI geçirmiş kadın hastaların cinsel yaşamlarını tanımlayıcı ve niteliksel bir araştırma ile incelemiştir. Bu çalışmaya göre, kalp krizi geçirme korkusu hastaların cinsel yaşamlarını negatif etkilediği, bu konuda sağlık personelinden destek alınılmadığı, kadınların MI sonrası eşleriyle cinsel ilişkiye girmeyi ret ettiği bulunmuştur.

Sundler, Dahlberg ve Ekenstam (2009)'ın 10 MI geçirmiş kadın hastada yaptığı kalitatif çalışmada, kadınlar MI sonrası cinsel tedirginlik yaşadığını, tekrar MI geçirme korkusu olduklarını ifade etmişlerdir.

Megiddo ve ark. (2009)'nın 104 kadında yaptığı çalışmada; normal cinsel ilişki, koroner arter hastalığı olanlarla karşılaştırıldığında koroner arter hastalığı olmayanlarda iki kat daha fazla görülmüştür.

Muller ve ark. (1996)'nın 858 MI (154 kadın) geçirmiş hastada yaptığ çalışmada; \%79 MI hastası 24 saat içinde cinsel ilişkide bulunmuş ve \%23'ü MI semptomlarından 2 saat öncesinde cinsel ilişkide bulunmuştur. Cinsel aktivite sonrası meydana gelen MI'ın rölatif riski 2,5 bulunmuştur (\%95 güven aralığı; 1,7$3,7)$. Önceden anjina hikayesi olan hastalarda MI için hedeflenen rölatif risk $(2,1$ [95\% CI, 0,8-5,8]) önceden kardiyak hastalığı olmayanlardan daha fazla değildir. Cinsel aktivite sırasında MI görülebilir. Ama rölatif riski düşüktür. Cinsel aktivite sadece $\% 0,9$ oranında MI'ya neden olabilmektedir. 
Merrigan (1998)'ın MI geçirmiş yaşlı 6 kadın hastada cinsel yaşamları ile ilgili niteliksel bir çalışma yapmıştır. Kadınların yaşı 65 ve üzeri, en az 3 hafta önce MI geçirmiş, bir yılı geçmemiş olan kadın hastalar çalışmaya alınmış. Yapılan görüşme de hastalar cinsel yaşamları ile ilgili korku yaşadıklarını, sorulması gereken sorunlar olunduğunu ifade edilmiş ve çalışmada cinsel danışmanlığın eksikliği vurgulanmıştır.

Arenhall, Kristofferzon, Fridlund ve Nilsson (2010)'un MI geçiren 20 kadın üzerinde yaptığı kalitatif çalışmada hastalar 'kayıp yaşam duygusu' sınırlı bir yaşam alanı've 'hayatın başka boyutu' şeklinde deneyimlerini ifade etmişlerdir.

Cinsellik yaşamın vazgeçilmez bir parçasıdır. Bu konuda sorun yaşandığında yaşamın diğer alanları ve sonuçta bütün olarak yaşam kalitesi olumsuz olarak etkilenir. Sağlık personelin temel fonksiyonu sağlığın korunması ve sağl1ktan sapmalar olduğunda gerekli yardımın yapılmasıdır. Bu nedenle kardiyovasküler hastalığı olan bireylere bakım veren sağlık personelinin hastaların cinsel fonksiyon durumlarını değerlendirmesi ve sorun varsa çözümü için uygun girişimlerde bulunması gereklidir (Ivarsson, Fridlund ve Sjöberg 2009; Y1ld1z ve Pinar 2004). MI sonras1 cinsel rehabilasyon süreci egzersiz, diyet, cinsel eğitimi, sigara bırakma, kilo verme ve sosyal desteği içerir. Bu süreç multidisipliner bir takım işidir (Djurović ve ark. 2010).

İrlanda'da ulusal olarak yapılan bir çalışmada koroner kalp hastalığına sahip olan hastalara yeterince cinsel eğitim verilmediği görülmüştür (Doherty, Byrne, Murphy ve McGee 2010).

Jaarsma ve ark. (2010)'nın 157 kardiyovasküler hemşiresinde yaptığ 1 çalışmada hemşirelerin beşte biri yeterli bilgiye sahipken, $\% 40$ ' 1 hastalarla cinsel sorunlarını tartışırken tereddüt hissetmektedir. Hemşireler hastaların \%67'sinin üzgün olduğunu, \%72'sinin utandığgnı ve $\% 68$ 'inin anksiyete yaşadıklarını ifade etmiştir.

Kardiyoloji hemşirelerin cinsellik ile ilgili bilgi ve tutumları $1994(\mathrm{n}=171)$ ve $2009(\mathrm{n}=288)$ tarihlerinde karşılaştırılmıştır. Yapılan eğitimlerin ve hemşirelerin tutumlarının 2009 yılında da eksik ve yanlış olduğu görülmüştür (Steinke, Mosack, Barnason ve Wright 2011a; Steinke, Mosack, Barnason ve Wright 2011b).

Kardiyologların, koroner arter hastalığına sahip hastaların cinsel aktivelerine geri dönmelerindeki danışmalıklarının değerlendirildiği çalışmada; $\% 58,6$ profesyonel, hastaların cinsel aktivitelerine hiç değinmemiştir. Bu durum cinsiyet, yaş, evlilik durumu ve akademik kariyerleri açısından hiçbir fark görülmemiştir (De Souza, Luiz Cardoso, S1lveira ve Martıns 2011).

Lunelli, Rabello, Stein, Goldmeier ve Moraes (2008) 66 hasta üzerinde yaptığ 1 MI sonrası cinsel aktivite çalışmasında, \%70'i erkek hasta ve \%80'i ilk MI deneyimine sahip olduğu, \%96 hastanın MI sonrası cinsellik ile ilgili bilgilerinin eksik olduğu, \%60 hasta hastaneden taburcu olduktan sonra cinsel yaşamlarında endişe yaşadıkları belirlenmiştir. Hastaların sadece \%4'ü hastanede kaldığ 1 sürece cinsellik ile ilgili danışmanlık almıştır.

Mosack ve Steinke'nin (2009) 1995 ve 2002 yılları arasinda 3 zaman diliminde (MI sonras1; 1 ve 2. aylar aras1, 3 ve 4 . aylar aras1, 5 ve 6 . aylar aras1) yaptığ 1 kalitatif çalışmada; üç zaman diliminde benzer sonuçlar bulunmuştur. Hastaların cinsel bilgileri yetersiz, cinsel yakınlaşmada endişe yaşamakta, hastanın ailesin ve çevresinin algıları hastayı etkilemekte ve cinsel korku yaşamaktadır.

Sağlık çalışanların, cinsel sorunları belirlemedeki engelleri: Sağlık çalışanların rahatsızlık hisetmesi, cinsellik hakında yetersiz bilgiye sahip olması, kardiyolojide çalışanların yaklaşımları, cinsel danışmanlığın bakımda önceliğinin düşük sayılması, hastanın anksiyetesini artırması, hastanın mahremiyetine girilmesi, çok hasta olması ve çalışma yükü nedeniyle zaman eksikliğidir. Ayrıca hastaların cinsel sorunları belirlemesinin sağlık çalışanlarından umut etmemesi, kültürel farklılıklar, sağlık çalışanların değerlerinin hastalardan farklı olması, sağlık çalışanların cinsel danışmanlığ1 yapmak istememesidir (Quote O’Donovan 2010b). 


\section{SONUÇ VE ÖNERILER}

Miyokard infarktüsü geçirmiş bir hastanın krizin hemen sonrasında kalbinin durumu cinsel ilişkiye tahammül etmeye uygun değildir. Cinsel ilişki esnasındaki efor, yaklaşık 2 katlı bir merdiveni hızla çıkmakla eşdeğer bir efordur: Bu efor esnasında kalp hızı ve kan basıncı artmaktadır. Genelde hastanın MI sonrası ilk 2 hafta içinde cinsel aktiviteye başlamaması önerilmektedir. Hasta stabilize olduktan 3-6 hafta sonra başlanılması daha güvenlidir (Chen ve ark. 2009; DeBusk 2000; Katz 2007; Quote O’Donovan 2010a). Hastalara sinirli ya da stres altında oldukları bir durumda cinsel aktiviteye başlamamaları, dinlenmiş, rahat, günlük yaşamın getirdiği gerilimlerden uzak, cinsel ilişki için rahat ve ilişkinin kesintiye uğramayacağ 1 bir yerin cinsel ilişki için tercih edilmesi önerilmelidir (Taylor 1999).

Miyokard infarktüsü sonrası kadınların cinsel yaşamı daha kapsamlı araştırılarak, gerekli cinsel eğitimin verilmesi sağlanmalıdır.

\section{KAYNAKLAR}

Altıok, M., Yılmaz, M. (2011). Opinions of individuals who have had myocardial infarction about sex. Sexuality and Disability, 29: 263-273.

Arenhall, E., Kristofferzon, M. L., Fridlund, B., Nilsson, U. (2010). The female partners' experiences of intimate relationship after a first myocardial infarction. Journal of Clinical Nursing, 20: 16771684.

Aygın, D., Aslan, F. E. (2008). Meme kanserli kadınlarda cinsel işlev bozukluklarının incelenmesi. Meme Sağllğ Dergisi, 4(2): 105-115.

Chen, X., Zhang, O., Tan, X. (2009). Cardiovascular effects of sexual activity. Indian Journal of Medical Research, 130: 681-688.

Dahabreh, I. J., Paulus, J. K. (2011). Association of episodic physical and sexual activity with triggering of acute cardiac events. JAMA, 305(12): 1225-1233.

De Souza, C. A., Luiz Cardoso, F., S1lveıra, R. A., Martıns, C. (2011). Management of sexual activity of coronary disease patients by the cardiologist. Acta Medica Portuguesa, 24(2): 249-254.

DeBusk, R. F. (2000). Evaluating the cardiovascular tolerance for sex. The American Journal of Cardiology, 86: 51F-56F.
Djurović, A. ve ark. (2010). Sexual rehabilitation after myocardial infarction and coronary bypass surgery: Why do we not perform our job? Vojnosanit Pregl, 67(7): 579-587.

Doherty, S., Byrne, M., Murphy, A. W., McGee, H. M. (2010). Cardiac rehabilitation staff views about discussing sexual issues with coronary heart disease patients: A national survey in Ireland. European Journal of Cardiovascular Nursing, 10: 101-107.

Drory, Y., Kravetz, S., Weingarten, M. (2000). Comparison of sexual activity of women and men after a first acute. The American Journal of Cardiology, 85(11): 1283-1287.

Drory, Y., Kravetz, S., Florian, V., Weingarten, M. (1998). Sexual activity after first acute myocardial infarction in middle-aged men: Demographic, psychological and medical predictors. Cardiology, 90: 207-211.

Eyada, M., Atwa, M. (2007). Sexual function in female patients with unstable angina or non-ST elevation myocardial infarction. The Journal of Sexual Medicine, 4: 1373-1380.

Hamilton, G. A., Seidman, R. N. (1993). A comparison of the recovery period for women and men after an acute myocardial infarction. Heart \& Lung: The Journal Of Critical Care [Heart Lung], 22(4): 308-315.

Ivarsson, B., Fridlund, B. ve Sjöberg, T. (2009). Information from health care professionals aboutsexual function and coexistence after myocardial infarction: A Swedish national survey. Heart Lung, 38: $330-335$.

Jaarsma, T. ve ark. (2010). Sexual counselling of cardiac patients: Nurses' perception of practice, responsibility and confidence. European Journal of Cardiovascular Nursing, 9: 24-29.

Katz, A. (2007). Sexuality and myocardial infarction. The American Journal of Nursing, 107(3): 49-52.

Kriston, L., Günzler, C., Agyemang, A., Bengel, J., Berner, M. M. (2010). Effect of sexual function on health-related quality of life mediated by depressive symptoms in cardiac rehabilitation, findings of the SPARK project in 493 patients. The Journal of Sexual Medicine, 7: 2044-2055.

Lunelli, R. P., Rabello, E. R., Stein, R., Goldmeier, S., Moraes, M. A. (2008). Sexual activity after myocardial infarction: Taboo or lack of knowledge? Arq Bras Cardiol, 90(3): 156-159.

Megiddo, E. ve ark. (2009). Sexual dysfunction and coronary artery disease in adult women. Harefuah [Harefuah], 148(9): 611-614.

Merrigan, M. A. T. (1998). The meaning of human sexuality to acute myocardial infarction clients who are older women. Adelphi University, ProQuest Dissertations\&Theses (PQDT), http://search. proquest.com/docview/304422213/fulltextPDF?accountid=11637 (10.09.2011) 
Morimoto, M. J. (2011). The effect of education about intimacy after a cardiovasculer event onn nurses' level of confort in patient support. Yayınlanmış Yüksek Lisans Tezi, California State University, Long Beach.

Mosack, V., Steinke, E. E. (2009). Trends in sexual concerns after myocardial infarction. Journal of Cardiovascular Nursing, 24(2): 162-170.

Muller, J. E., Abela, G. S., Nesto, R. W., Tofler, G. H. (1994). Triggers, acute risk factors and vulnerable plaques: Lexicon of a new frontier. J Am Coll Cardiol, 23(3): 809-813.

Muller, J. E., Mittleman, M. A., Maclure, M., Sherwood, J. B., Tofler, G. H. (1996). Triggering myocardial infarction by sexual activity. JAMA, 275: 1405-1409.

Özdemir, L., Akdemir, N. (2010). Nurses' knowledge and practice involving patients' resuming sexual activity following myocardial infarction: Implications for training. Australian Journal of Advanced Nursing, 26(1): 42-52.

Özer, Z., Bektas, H., Arikan, F., Vicdan, N. (2011). Sexual dysfunction and quality of life in female and male patients with myocardial infarction. Journal of Sexual Medicıne, 8: 424.

Papadopoulos, C., Beaumont, C., Shelley, S. I., Larrimore, P. (1983). Myocardial infarction and sexual activity of the female patient. Arch Intern Med., 143(8): 1528-1530.

Quote O’Donovan, K. (2010a). Helping patients cope after MI. World of Irish Nursing \& Midwifery (WIN), 18(2): 33-34.
Quote O'Donovan, K. (2010b). Sexual activity after myocardial infarction, Continuing Education, Module 16. World of Irish Nursing \& Midwifery, 18(1): 29-31.

Stein, R. A. (2000). Cardiovascular response to sexual activity. The American Journal of Cardiology, 86: 27F-29F.

Steinke, E. E., Mosack, V., Barnason, S., Wright, D. W. (2011a). Changes in myocardial infarction-specific sexual counseling by cardiac nurses. Dimensions of Critical Care Nursing, 30(6): 331338.

Steinke, E. E., Mosack, V., Barnason, S., Wright, D. W. (2011b). Progress in sexual counseling by cardiac nurses, 1994 to 2009. Heart \& Lung, 40(3): e15-e24.

Sundler, A. J., Dahlberg, K., Ekenstam, C. (2009). The meaning of close relationships and sexuality: Women's well-being following a myocardial infarction. Qualitative Health Research, 19(3): 375387.

Taylor, H. A. (1999). Sexual activity and cardiovascular patient: Guidlines. The American Journal of Cardiology, 84: 6N-10N.

Yıldız, H., Pınar, R. (2004). Miyokard infarktüslü hastalarda cinsel disfonksiyon. Anadolu Kardiyoloji Dergisi, 4: 209-217.

Yılmaz, H. ve Pınar, R. (2005). Cinsel disfonksiyonu olan kardiyovasküler hastaların bakımı. Ege Üniversitesi Hemşirelik Yüksek Okulu Dergisi, 21(2): 135-145. 